\title{
RAWLS: LIMITES DA CONSTITUIÇÃO INTERNACIONAL DA JUSTIÇA*
}

Sônia T. Felipe**

SÍNTESE - Este artigo revisa as criticas apontadas por Pablo da Silveira à teoria da justiça de John Rawls, proposta para ordenar uma sociedade dos povos. Os problemas da estabilidade, do consenso justaposto e da razão pública, tratados por Rawls de forma insatisfatória em sua obra mais recente, The Law of Peoples, são aqui revisitados, no intuito de verificar a pertinência daquelas críticas e as implicaçōes para a teoria da justiça de Rawls, da substituição dos conceitos de cidadão pelo de povo e consenso justaposto por consenso constitucional, razão politica por razão pública. Considero, criticamente, que tais substituiçōes têm implicações tanto no âmbito doméstico quanto internacional, podendo fomentar a apatia do cidadão no que diz respeito à participação direta nos assuntos politicos.

PALAVRAS-CHAVE - Justiça. Rawls. Consenso Justaposto. Consenso Constitucional. Apatia Política. Razão Pública. Constituição. Personalidade Moral. Cidadão.
ABSTRACT - This article reviews the criticisms raised by Pablo da Silveira to John Rawls's theory of justice, as for the ordering of a society of peoples. The problems of stability, overlapping consensus and public reason, poorly dealt with by Rawls in his most recent work. The Law of Peoples, are revisited here, with a view to addressing the relevance of these criticisms and their implications for Rawls's theory of justice, as the originary concepts of citizen, overlapping consensus, and political reason are respectively replaced by those of people, constitutional consensus, and public reason. I argue that such replacements have implications both for domestic and for international spheres, eventually furthering citizens' apathy insofar as their direct participation in political matters is concerned.

KEY WORDS - Citizen. Constitution. Constitutional Consensus. Justice. Moral Personality. Overlapping Consensus. Political Apathy. Public Reason. Rawls.

* Apresentado no IX Encontro Nacional da ANPOF, 03-08/10/2000, Poços de Caldas, MG no GT Teorias da Justiça.

** Doutora em Teoria Política e Filosofia Prática pela Universidade de Konstanz-Alemanha (1991). Professora de Ética e de Filosofia Politica no Departamento de Filosofia da UFSC. Coordenadora do Núcleo de Estudos em Ética e Filosofia Política. Orientadora do LEP - Laboratório de Textos em Ética Prática, dos estudantes de graduação em Filosofia da UFSC. Co-fundadora do Núcleo de Estudos Interdisciplinares sobre a Violência (1993). Co-autora dos livros $O$ corpo violentado e $A$ violência das mortes por decreto. Co-organizadora do I Simpósio Internacional sobre a Justiça (Florianópolis, 1997). Organizadora de Justiça como Eqüidade; Anais do I Simpósio Intemacional sobre a Justiça. Coordenadora do Núcleo de Formação em Direitos Humanos (trabalho voluntário) do Centro de Direitos Humanos da Grande Florianópolis.

\begin{tabular}{l|l|l|l|l|l|}
\hline VERITAS & Porto Alegre & v. 45 & n. 4 & Dezembro 2000 & p. 615-632
\end{tabular}


Analiso, no presente artigo, os limites e avanços da teoria da justiça de Rawls apontados por Pablo da Silveira no I Simpósio Internacional sobre a Justiça. Há aspectos problemáticos, na transposição ou extensão de Uma teoria da Justiça (UTJ:1971) pensada inicialmente para o âmbito doméstico - o da ordenação, em uma dada democracia, das instituições responsáveis pela distribuição justa dos bens sociais primários e dos públicos - para a obra The Law of Peoples (LOP: 1999) - escrita para ordenar uma Constituição dos Povos. Rawls considera nessa última obra um dos campos da ética que haviam sido classificados em UTJ, como parte do que denominou, então, problema de extensão de sua teoria, qual seja, o da justiça entre os povos, e não entre cidadãos cooperativos.

$\mathrm{Na}$ categoria dos problemas de extensão Rawls inclui a questão da distribuição justa de bens, materiais e imateriais, primários, sociais e públicos, entre sujeitos não cooperativos entre si, seja no período da presente geração (justiça intrageracional), seja no tempo que abrange esta e as gerações futuras (justiça intergeracional). ${ }^{1}$ Fazem parte, no entender de Rawls, do problema da extensão, as questões éticas que envolvem deveres ou obrigações em relação às pessoas doentes, aos deficientes, aos bebês, aos idosos, aos estrangeiros, aos animais e a todos os povos que, de acordo com The Law of Peoples, se encontram em condições hostis à implementação das instituições da justiça para regular a distribuição de bens.

Ambientalistas e defensores dos seres não capazes de exercerem poderes morais, ${ }^{2}$ têm criticado o modelo de justiça de Rawls, por considerá-lo incapaz de dar respostas aos problemas que envolvem o dever de respeitar ou de preservar os interesses daqueles que não fazem parte do sistema de cooperação social, seja em uma sociedade liberal, seja em outra sociedade orientada por uma concepção não liberal, portanto, não política de justiça.

Em The Law of Peoples Rawls experimenta o alcance de sua teoria da justiça ao propor uma Constituição dos Povos com vistas à preservação da liberdade e da paz no âmbito internacional. Algumas questões continuam sem solução no texto revisto entre 1993 - ano da Conferência sobre os Direitos Humanos, oferecida por Rawls, em Oxford, a convite da International Amnesty - e 1999, ano de publicação de The Law of Peoples. Apresento a seguir as críticas feitas por Pablo da Silveira àquele texto, e as respostas dadas por Rawls em seu texto recente.

Pablo da Silveira questiona, no modelo de Rawls, ${ }^{3}$ a inexistência de esclarecimentos sobre a possibilidade de se garantir a justiça entre gerações (problema da

1 O problema da justiça intergeracional na distribuição de bens públicos é objeto da tese de doutorado interdisciplinar Sociedade e Meio Ambiente, do Centro de Filosofia e Ciências Humanas da UFSC, escrita por Vicente Volnei de Bona Sartor, o qual investiga duas questões centrais à teoria da justiça de Rawls: bens primários públicos e justiça intergeracional, vinculadas à questão da distribuição justa de bens naturais, em especial, da água.

2. Peter SINGER, em seu livro Ética Prática (Martins Fontes 1993) apresenta uma critica ao modelo de igualdade sugerido por Rawls para resolver a questão da justiça entre seres dotados de capacidades desiguais, ainda que pertençam à espécie Homo sapiens. Ver em especial o Cap. 2: Da igualdade e suas implicações, na referida obra.

3 FELIPE, Sônia T. (Org.) Justiça como Eqüidade. Anais do Simpósio Internacional sobre a Justiça. Florianópolis: Insular, 1998. 413 p. Retomo aqui, de forma resumida, a crítica de Pablo da Silveira, 
estabilidade), e a compatibilização da diversidade ou pluralidade moral em uma única concepção política pública de justiça (problema do consenso justaposto), em um contexto político e cultural no qual reina, por um lado, a apatia do cidadão, e, por outro lado, a multiculturalidade de tradições não liberais.

A pluralidade de Estados é possivel de ser tolerada, assim o entende o crítico de Rawls, enquanto se mantém estável a correlação de forças entre eles. O mesmo já não acontece no interior de um dado Estado. No caso dos cidadãos não é a correlação de forças, ou seja, a possibilidade da igualdade e da reciprocidade no uso da violência, que os mantém no pacto de não-agressão, mas, seu modus vivendi. Ao não se ocupar Rawls, quando estende sua teoria para o plano internacional, da estrutura básica das sociedades, mas, apenas dos procedimentos democráticos (consenso constitucional), ainda que tenha dado um passo adiante em relação à concepção intuicionista de justiça (filiação ao modus vivendi) deixa muito a explicar e a resolver.

Há três níveis de elaboração do consenso, deduz-se do que Pablo da Silveira analisa criticamente: o modus vivendi, saída encontrada por todos os grupos que reconhecem a impossibilidade de manter relações hostis com aqueles que divergem em suas concepções de bem; o consenso constitucional, segundo nível de desenvolvimento da razão, a qual não se ocupa apenas de apontar o que é mais vantajoso para os adeptos a uma determinada concepção de bem, mas procura institucionalizar formas de convivência tolerante para garantir no seio da comunidade política a presença e a integridade de cidadãos não filiados à tradição de um determinado grupo; e o consenso justaposto, que representa, na verdade, a passagem da razão, de seu interesse particularmente afetado pela intuição, ao interesse universal propriamente dito, ou seja, da habilidade de calcular, com vistas ao plano racional de vida orientado por uma concepção privada de bem, a forma mais eficiente de satisfazer os interesses próprios, à reflexão sobre princípios que assegurem imparcialmente a todos os cidadãos a possibilidade de exercerem seus poderes morais. Esses três momentos são expressões da racionalidade humana em direção à razoabilidade política. ${ }^{4}$

Pablo da Silveira concede que, teoricamente, a proposta do consenso justaposto supera as deficiências da filiação tradicional à intuição que fomenta os próprios interesses (modus vivendi) e alcança maior profundidade e abrangência em relação ao consenso constitucional. Mas, praticamente, Rawls não leva em conta que somente sociedades de cidadãos muito evoluídos podem alcançar o consenso

apresentada sob o título: "La teoría rawlsiana de la estabilidad: consenso justaposto, razón pública y discontinuidad", p. 345-363.

4 Essas observações resumem o exposto por Rawls em Political Liberalism (PL) ao tratar da distinção entre racionalidade e razoabilidade, e em The Law of Peoples (LOP) ao teorizar sobre a evolução politica da racionalidade humana, que conduz as sociedades humanas do modus vivendi, saida encontrada para fazer frente às intolerâncias mais radicais, ao consenso justaposto (Cf. LOP: Part I, The first part of ideal theory, p. 11-58), expressão mais elevada, no plano político, da razoabilidade, traduzida por sua vez, no cumprimento da exigência de reciprocidade (Cf. PL: Lecture II, § 1, p. 4854). 
justaposto. No intuito de não submeter os juizos morais pessoais à intervenção do Estado Rawls confunde, afirma Pablo da Silveira, razão pública com razão política. Em seu modelo Rawls não dá espaço para a discussão dos conteúdos das concepções amplas de justiça (razão política) representadas na multiculturalidade que requer o consenso justaposto.

Pablo da Silveira enfatiza a necessidade de explicitação das diferentes concepções particulares de bem, pois, sem a liberdade de expressão pública das diversas interpretações de uma idéia, tal como, por exemplo, a da justiça, não há consenso justaposto entre cidadãos. Assim, a teoria da justiça, seja no âmbito doméstico seja no internacional, não tem como assegurar sua estabilidade, pois essa depende, ao mesmo tempo, da psicologia moral dos sujeitos ${ }^{5}$ e do pluralismo de morais pessoais vigentes em dada sociedade, ou seja, da capacidade dessa sociedade de manter o vínculo de cooperação social entre sujeitos filiados a concepções divergentes, ainda que amplas, de bem (comprehensive theories). ${ }^{6}$

No entender de Pablo, justamente por querer Rawls evitar que as concepções privadas de bem - concepções gerais e abrangentes, mas não compartilhadas por todos - definam a concepção política de justiça, acaba bloqueando, no âmbito mesmo de sua proposta, a possibilidade do consenso justaposto entre sujeitos filiados às diversas concepções. Pablo reconhece que o consenso justaposto tornase consenso entre teorias e não entre indivíduos. ${ }^{7}$ Adotada e exercida uma determinada concepção privada de bem, ela é razoável se não ameaça abolir o poder moral daqueles que não a adotam. ${ }^{8}$ Não resulta, necessariamente, dessa tolerância teórica, a vinculação e aceitação entre os indivíduos. ${ }^{9}$

Tal consenso justaposto, no entender de Pablo da Silveira, depende da cultura de fundo, que assegura a estabilidade do modelo de justiça através das gerações. Ao não tratar, no texto de $1993,{ }^{10}$ do papel da cultura de fundo, entendido por

6 A estabilidade do modelo de justiça depende do processo de introjeção do sentido de justiça, trabalhado por Rawls nos capitulos VII, VIII e IX, Terceira Parte de sua primeira obra. Cf. John Rawls. Uma teoria da justiça. São Paulo: Martins Fontes, 1997.

6 Pablo indica três elementos que constituem uma teoria geral e abrangente do bem, ou o que Rawls denomina comprehensive theories: 1.) idéias sobre o que tem valor para a vida humana; 2.) idéias sobre como conduzir-se nas amizades, associações e vínculos familiares; 3.) idéias sobre o melhor modo de se viver em comum. Uma teoria ampla do bem inclui, assim, ao mesmo tempo, de acordo com a interpretação de Pablo da Silveira, idéias para orientar o sujeito tanto em relação às questões políticas, quanto não politicas. Por essa razão é considerada uma concepção geral e abrangente do bem. Cf. Pablo da Silveira, In: Justiça como Eqüidade, p. 347.

7 Ibid., p. 349.

8 Nesse caso confirma-se o caráter tolerante da mesma, condição sine qua non de participar do pacto constituinte da estabilidade. Ibid..

9 Para interpretar o consenso justaposto Pablo sugere três diferentes maneiras: $1^{\mathrm{a}}$. O consenso, conforme dito acima, não é entre indivíduos filiados às distintas concepções privadas de bem, mas entre essas mesmas, que forjam um conceito político de justiça; $2^{a}$. O consenso é consenso entre concepções gerais e abrangentes de bem que aceitam o conceito e a concepção de poder moral extensivos a todos os não filiados a elas; $3^{\mathrm{a}}$. $\mathrm{O}$ consenso é o que resulta do processo particular de adesão de cada uma das concepções amplas à concepção política de justiça proposta. Cf. Ibid., p. 348-349

10 Conferência feita na Anistia Internacional sobre Direitos Humanos, que deu origem ao livro The Law of Peoples. 
Pablo como problema central à democracia no multiculturalismo e no pluralismo de concepções amplas e abrangentes do bem, Rawls fracassa em garantir a estabilidade ao projeto do consenso justaposto. ${ }^{11}$

O Autor afirma ser frágil o consenso justaposto entre teorias proposto por Rawls, por um lado, devido ao conteúdo do conceito de autonomia moral e pessoal, herança kantiana que não tem nada a ver com as concepções gerais e abrangentes de bem, praticadas, por exemplo, por "tribalistas" e por "hedonistas", ${ }^{12}$ os quais não gostam nem do reconhecimento nem da declaração de tal autonomia individual do sujeito. ${ }^{13}$ Antes do direito individual naqueles grupos conta o direito à integridade da comunidade local, nacional ou internacional. Todas as ações políticas são empreendidas em seu nome. A ela devem servir os projetos pessoais de vida. Nessas tradições, declarar autonomia individual pode significar a condenação do indivíduo à própria sorte. Afirmar que esse deve fundar em si mesmo o sentido da existência, pode ser algo aceito na tradição liberal ocidental, mas não recebe fundamento em outras concepções privadas de bem oriundas de outras fontes religiosas e filosóficas. Desde Aristóteles que a autonomia e a deliberação, bem como a ética delas derivada, estavam fundadas no pressuposto da propriedade que dava, por sua vez, ao homem, a liberdade para exercer o raciocínio em função do plano que o conduz à preservação de si mesmo como senhor livre entre os muitos outros igualmente dotados de liberdade e propriedade. Um dos problemas do liberalismo, justamente, é não conseguir garantir a todos os cidadãos a liberdade oriunda da propriedade. Declara-se que o indivíduo é autônomo, responsabiliza-se o mesmo pela obtenção dos bens primários essenciais à integridade de seu corpo e à realização de um projeto racional de vida, e abandona-se o mesmo à sorte indefinida pelo mercado.

Ao não dar solução aos problemas que decorrem do desinteresse pela atividade política, por parte daqueles que não concordam com o conceito de autonomia pessoal e moral sugerido como ponto de partida pela tradição democráticoconstitucional liberal da justiça, a teoria de Rawls começa a apresentar lacunas. Pablo reconhece como problemática para a democracia a apatia política nos planos doméstico e internacional. ${ }^{14}$

É verdade que Rawls, em The Law of Peoples, cede às críticas dos não liberais e deixa de enfatizar o conceito de personalidade moral tão caro aos liberais, desenvolvido em Political Liberalism. ${ }^{15}$ Mas, ao invés de propiciar o consenso entre cidadãos filiados a diferentes concepções privadas de bem, tal estratégia acaba

" Pablo da Silveira, Ibid., p. 357

${ }_{12}$ Ibid., p. 357

13 O próprio Rawls, referindo-se à concepção de pessoa em sociedades hierárquicas declara: “... a decent hierarchical society has never had the concept of one person, one vote, which is associated with a liberal democratic tradition of thought that is foreign to it, and perhaps would think (as Hegel did) that such an idea mistakenly expresses an individualistic idea that each person, as an atomistic unit, has the basic right to participate equally in political deliberation." LOP, p. 73

${ }_{14}$ Pablo da Silveira, Ibid., p. 359

15 Cf. Lecture III: Political Constructivism, p. 89-129 
por afastar ainda mais o cidadão do espaço político de discussão, no qual poderia explicitar suas diferenças em relação às concepções diversas de um modelo de justiça aparentemente incompatíveis com suas crenças privadas de bem. Pois, se é verdade o que Pablo afirma, que o consenso político real se estabelece ou deixa de se estabelecer não entre teorias (consenso ideal), mas entre indivíduos, esses deveriam ser chamados à participação política, ainda que em um primeiro momento essa participação seja restringida à explicitação das diferenças de conceito e de concepção de justiça.

Penso que parte daquela apatia à qual Pablo se refere deva-se justamente à frustração resultante do fato de que, tanto nas democracias representativas quanto em outras formas de governo, parece que bastam alguns para procederem à análise da viabilidade do consenso teórico, enquanto os muitos (polis), os quais sustentam de fato a atividade da cultura de fundo, em uma sociedade democrática liberal, não são convidados ao debate público sobre as exigências da justiça. ${ }^{16} \mathrm{Em}$ todas as atividades que constituem a cultura de fundo os cidadãos permanecem, então, regidos por convicções privadas do bem, provenientes de sua tradição ou intuição. Na hora de fazer política a maioria se esquiva, pois o espaço da política é justamente o espaço no qual expressam-se as divergências. Por não terem sido trabalhadas essas divergências nos espaços culturais mais amplos, acumula-se a carga emocional de intolerância, que, ao se manifestar, produz horror a todos os que nela se envolvem. Não há, desse modo, espaço para aqueles e aquelas que gostariam de fazer política sem clima de guerra. Como poucos são os homens que gostam dessa forma de atuação, a política acaba 'selecionando' apenas um determinado tipo de cidadão, e excluindo a grande maioria.

Pablo conclui, conforme escrito acima, haver confusão, no texto de Rawls, entre razão política e razão pública. Penso que seria mais correto dizer que Rawls reduziu a razão política à razão pública, esquecendo-se que nem tudo o que é público é político. A razão pública é esforço de justificação dos atos políticos, isto é, das decisões tomadas pelos que exercem o poder, em nome do interesse comum. Mas, tal esforço de justificação não inclui a participação dos cidadãos no processo de decisão mesmo, a não ser, gostaria de acrescentar, nos poucos cantões suíços, nos quais se exerce a democracia participativa direta. A suspeita de Pablo, de que Rawls confunde as duas formas de expressão da razão, a política e a pública, confirma-se, julgo, com a publicação do texto The Idea of Public Reason Revisited, ${ }^{17}$ no qual o Autor esclarece sua idéia de razão pública:

16 Quando se discute em público, o que aparece são: 1.) idéias sobre o que tem valor para a vida humana; 2.) idéias sobre como conduzir-se nas amizades, associações e vínculos familiares; 3 .) idéias sobre o melhor modo de se viver em comum, que Pablo da Silveira considera típico das doutrinas amplas e particulares de bem. Cf. nota 6 acima. Quando se trata de políticas públicas em todos esses setores: universidades, artes, mídia, igrejas, não se discute, jamais, sobre a aplicação dos princípios da liberdade, da igualdade e do princípio da diferença.

1 RAWLS, John. The Law of Peoples; with "The Idea of Public Reason Revisited". Cambridge MA/London UK: Harvard University Press, 1999. p. 129-180. 
"[...] é preciso compreender que a idéia da razão pública não se refere a todas as discussões politicas sobre questões fundamentais, mas somente às discussões daquelas questões que denomino de fórum político público. Esse fórum pode ser dividido em três partes: 0 discurso dos juizes em suas decisões, especialmente o dos juizes do supremo tribunal federal; o discurso dos funcionários do governo, especialmente dos chefes do executivo e dos legisladores; e por último, o discurso dos candidatos aos cargos públicos e de seus chefes de campanha, especialmente em sua oratória pública, plataforma política e declarações políticas. [...] Distinta e separada desse fórum político público tripartite, encontra-se o que denomino de cultura de fundo. Essa é a cultura da sociedade civil. Em uma democracia essa cultura, obviamente, não é guiada por uma idéia ou princípio central qualquer, seja política ou religiosa. Suas várias e diversificadas agências e associações com sua vida própria, se estabelecem no âmbito da lei que assegura as liberdades tradicionais de pensamento e de expressão, e o direito à livre associação. A idéia da razão pública não se aplica à cultura de fundo, com suas diversas formas de razão não pública, nem à mídia de qualquer espécie."${ }^{18}$

Justamente o espaço que congrega as atividades humanas, ou a atividade dos muitos traduz no processo de produção de bens materiais e imateriais, cuja atividade oferece a todos os cidadãos oportunidade para que possam buscar a felicidade, o verdadeiro sentido do bem comum, em nome do qual se constrói o modelo de justiça. Esse é, no meu entender, seguindo o alerta feito por Pablo sobre a fusão dos dois conceitos em Rawls, o espaço da razão política, no qual dever-se-ia expressar as diversas concepções particulares de bem, antes de se construir a concepção política de justiça para as instituições. Concordo com Pablo que é desse espaço que devem sair as diretrizes para a formação do consenso constitucional. Rawls exclui os cidadãos da razão pública, tanto quando expressa sua idéia de razão pública, quanto ao falar do ideal da mesma. O ideal da razão pública é realizado, no seu entender, quando:

"[...] juizes, legisladores, chefes do poder executivo e outros funcionários do governo, bem como candidatos aos cargos públicos, agem com base em e seguindo a idéia da razão pública e explicam aos outros cidadãos suas razões para apoiar posições políticas fundamentais de acordo com a concepção política de justiça que consideram mais razoável. ${ }^{19}$

18 "... It is imperative to realize that the idea of public reason does not apply to all political discussions of fundamental questions, but only to discussions of those questions in what I refer to as the public political forum. This forum may be divided into three parts: the discourse of judges in their decisions, and especially of the judges of a supreme court; the discourse of government officials, especially chief executives and legislators; and finally, the discourse of candidates for public office and their campaign managers, especially in their public oratory, party platforms, and political statements. (...) Distinct and separate from this three-part public political forum is what I call the background culture. This is the culture of civil society. In a democracy, this culture is not, of course, guided by any one central idea or principle, whether political or religious. Its many and diverse agencies and associations with their internal life reside within a framework of law that ensures the familiar liberties of thought and speech, and the right of free association. The idea of public reason does not apply to the background culture with its many forms of nonpublic reason nor to media of any kind." RAWLS, Ibid., p. 133-134 
É preciso considerar, ainda, os elementos que constituem a estrutura da idéia da razão pública, a fim de não confundi-la com o ideal da razão pública. Ela está constituída de cinco elementos:

“(1) a questão política fundamental a qual se refere; (2) as pessoas às quais diz respeito (funcionários do governo e candidatos aos cargos públicos); (3) seu conteúdo, estabelecido a partir de um conjunto de concepções tradicionais de justiça; (4) a aplicação desses conceitos nas discussões sobre normas coercitivas a serem adotadas por lei para o povo democrático; (5) cidadãos conferindo se os princípios derivados dessa concepção de justiça satisfazem o critério da reciprocidade. ${ }^{\text {"20 }}$

Se, então, a razão pública, enquanto ideal é realizada em sua maior parte pelos ocupantes do judiciário, executivo e legislativo, confirma-se minha suspeita, em decorrência daquilo que Pablo denomina de apatia política, de que talvez a dificuldade de se estabelecer o consenso justaposto ocorra, nas democracias representativas, justamente porque os cidadãos não são convocados a explicitarem suas divergentes opiniōes, fundadas em crenças privadas, acerca do bem que o Estado democrático afirma querer assegurar igualmente para todos.

Rawls tenta, ao que me parece, na nota de rodapé número 15 de The Idea of Public Reason Revisited, ao citar David Hollenbach, preencher a lacuna resultante de sua própria definição do ideal da razão pública, na qual apenas os mandatários do poder são considerados, e os demais cidadãos colocados não como proponentes do conteúdo da política, mas apenas como fiscais dos atos de seus representantes. Hollenbach, na passagem escolhida por Rawls, reconhece a atividade das universidades, das comunidades religiosas, do mundo artístico e do jornalismo sério - como fomentadores daquilo que Rawls denomina de cultura de fundo (background culture) $^{21}$ - espaços da liberdade de pensamento e de expressão nos quais as discussões sobre a vida boa são realizadas. Rawls distingue e separa, conforme se pôde ver em sua definição da idéia de razão pública, essa esfera, da esfera política propriamente dita.

$\mathrm{O}$ que nem Rawls nem Hollenbach percebem, ao considerarem contemplada a questão da substância teórica que deve fomentar os debates da razão pública, é que, excluídas da responsabilidade de produção de uma teoria política razoável de justiça, todas essas esferas da atividade da sociedade civil podem ser freqüentadas como se fossem esferas enclausuradas em si mesmas, sem que se chegue jamais, em alguma delas, a estabelecer um debate público verdadeiramente amplo (razoável) sobre a concepção de justiça que realmente se quer ver realizada pelo estado democrático.

\footnotetext{
20 "It has five different aspects: (1) the fundamental political questions to which it applies; (2) the persons to whom it applies (government officials and candidates for public office); (3) its contents as given by a family of reasonable political conceptions of justice; (4) the application of these conceptions in discussions of coercive norms to be enacted in the form of legitimate law for a democratic people; and (5) citizens' checking that the principles derived from their conceptions of justice satisfy the criterion of reciprocity." Ibid., p. 133

${ }^{21}$ Cf. Nota de rodapé n. 15 à p. 134-135 de The Law of Peoples.
} 
Insisto, ainda uma vez, que é possivel deduzir do fato de que o consenso justaposto não precisa ser forjado entre cidadãos, desde que alguns concluam que já se encontra dado entre teorias, que esses mesmos cidadãos não podem, sozinhos, sem terem eles mesmos, acompanhado e produzido a elaboração dos argumentos que concluem pela possibilidade do consenso, superar a intolerância natural a cada concepção privada de bem em relação às demais. É como se as teorias fossem racionais, sem que se permita aos cidadãos que desenvolvam sua capacidade de raciocínio, fundamental à razoabilidade, que é a capacidade de pensar em realizar um determinado projeto levando em conta os interesses dos que serão afetados por ele (exigência de reciprocidade).

Há lacunas, ainda, na teoria de Rawls, já o notara Pablo, com relação ao fato de que minorias de tradição não liberal, que desejam ter sua forma própria de governo, acabam tendo de ceder, pelo menos em parte, aos princípios liberais, de acordo com os quais o consenso constitucional - ou, usando agora a expressão que Rawls sugere em The Idea of Public Reason, o ideal da razão pública, é estabelecido e o governo funciona. ${ }^{22}$ Por fim, resta ainda a questão das tradições nãodemocráticas, mas não no âmbito doméstico ou das minorias não democráticas migradas para dentro de regimes democráticos, e sim no âmbito internacional, o que significa, resta silêncio e lacuna na teoria de Rawls, em relação à questão da paz internacional que, por limitação de espaço, não posso abordar nesse texto. ${ }^{23}$

Pablo reconhece, no consenso constitucional, em concordância com a explicitação de Kurt Baier, uma etapa superior à do modus vivendi. Através do consenso constitucional são definidas, para que os governantes se orientem, as regras do jogo democrático. The Law of Peoples, no entanto, quer estabelecer os moldes para uma constituição dos povos. Mas, justamente por se limitar ao âmbito do consenso constitucional, isto é, à definição das regras do jogo democrático no plano internacional, silencia, no entender de Pablo da Silveira, sobre quatro questões fundamentais à justiça distributiva:

$1^{\text {a) }}$ À do alcance dos direitos políticos básicos;

$2^{\text {a) }}$ À da solução para os conflitos que resultam da concorrência desses direitos entre si;

3a) À da igualdade de oportunidades;

4ª) À da destinação de recursos para assegurar os bens básicos aos indivíduos. $^{24}$

Por silenciar sobre essas questões, o consenso constitucional não assegura "sua própria estabilidade", não "vincula suas normas e principios às noções am-

22 Pablo da Silveira, Ibid., p. 360

${ }^{23}$ Ibid., p. 360. Rawls dá atenção a esse ponto em The Law of Peoples, Part II: The Second Part of Ideal Theory, p. 59-88. Meu artigo apresentado no II Simpósio Internacional sobre a Justiça, realizado de 21 a 25 de agosto de 2000, na PUC de Porto Alegre, trata da questão da guerra, e da defesa retórica dos direitos humanos, feita por Rawls em The Law of Peoples, questões que contemplam a relação de povos liberais com povos fora-da-lei.

${ }^{24}$ Cf. Pablo da Silveira, Op. cit., p. 350 
plas, às quais os indivíduos se filiam para aceitá-los". ${ }^{25}$ Se o consenso constitucional é o ideal da razão pública praticado pelos mandatários do poder, e se esse ideal de fato se realiza quando eles discursam em público para justificar suas posições, é preciso reconhecer definitivamente o veio autoritário no qual se faz transportar o modelo de Rawls para definir a concepção de justiça e suas práticas no plano internacional: a razão pública permanece confinada ao reduto dos atos do governo.

Se, de fato, os cidadãos não são chamados para discutir em um Fórum público suas diferenças, se apenas os que detêm o poder pronunciam para um público passivo de cidadãos os discursos justificadores de suas decisões, como se pode esperar participação política? A um observador imparcial pode ficar bem claro que não há diferença entre a passividade de um cidadão que, em um regime fundamentalista, assiste pela TV os discursos legitimadores das decisões tomadas pelos que detêm o poder, e a passividade do cidadão de uma democracia liberal, na qual a liberdade de expressão é exercida em clausuras (igrejas, mídia, sindicatos, universidades) mas, assim como no exemplo anterior, os discursos dos governantes sobre o bem comum também são transmitidos pela TV, na qual os políticos aparecem para justificar, quando o conseguem, seus atos. O autoritarismo na política contemporânea arrisco afirmar, não é de forma alguma exclusividade do mundo fundamentalista, islâmico ou comunista.

Vejamos como Rawls dá encaminhamento, no texto publicado em 1999, The Law of Peoples, aos problemas e questões do texto de 1993, apontados por Pablo. O primeiro dos quatro problemas relaciona-se aos direitos políticos básicos dos cidadãos em uma Constituição dos Povos. Logo no início de LOP Rawls trata de esclarecer a distinção entre dois conceitos centrais da justiça: o de cidadão conceito próprio para tratar da justiça no âmbito doméstico, e o de povo - conceito de cidadão não mais pessoalmente atuante, mas ator que atua através de seus governantes, figura própria à teoria da justiça no plano internacional. ${ }^{26}$

Enquanto cidadão o indivíduo é concebido na posição original, como uma pessoa moral, isto significa, um ser dotado de liberdade, igual aos demais, racional e razoável, o qual por assim ser respeitado, entra no sistema de cooperação social e deseja a estabilidade do mesmo de sua presente geração à seguinte.

Ao passar do âmbito da teoria da justiça doméstica para o internacional, não são mais os cidadãos que portam as qualidades específicas da personalidade moral, ou os poderes morais, mas, os povos, que agora sabemos, são representados pelos seus governantes no âmbito internacional..$^{27}$ Rawls responde, assim, a Pablo da Silveira, ainda que desconheça tais críticas, declarando que, enquanto os cidadãos têm interesses básicos ${ }^{28}$ - Pablo questiona sobre os direitos básicos do cidadão no plano da Constituição dos Povos - os povos têm interesses fundamentais a

Ibid., p. 350

RAWLS, LOP, p. 23

Ibid., p. 30

Cf. Ibid., p. 31 
proteger: independência política, cultura livre, liberdades civis, segurança, bemestar, respeito próprio (aqui Rawls refere-se ao amor próprio em Rousseau). ${ }^{29}$

Rawls distingue ainda entre povos e Estados. Estes são menos do que aqueles propensos a atuar moralmente. Povos têm - apesar das desigualdades políticas e econômicas que os separam -, mais convicção da igualdade recíproca do que os Estados. Estes são menos propensos à ação fundada em princípios morais de respeito igual. A igualdade entre Estados, lembra Pablo, o qual cito no início do presente texto, dá-se não por um princípio moral, mas pela correlação de forças. Por isso Rawls sugere uma Constituição dos Povos, conforme prefiro traduzir seu projeto, e não uma Constituição dos Estados. Tal constituição deve assentar em um princípio moral, isto é, universalmente válido, e não em princípios racionais adotados pelos Estados para atenderem exclusivamente interesses particulares.

"[...] O que distingue povos de estados - e isso é crucial - é justamente que os povos estão dispostos a garantir o mesmo respeito e reconhecimento a outros povos como iguais. Sua igualdade não significa, no entanto, que desigualdades de alguma espécie não sejam toleradas em diversas instituiçōes cooperativas entre povos, tais como a das Nações Unidas, concebida idealmente. O reconhecimento dessas desigualdades, pelo contrário, se coaduna com a aceitação por parte dos cidadãos, de desigualdades funcionais, sociais e econômicas em sua sociedade liberal." ${ }^{30}$

A segunda das quatro questões levantadas por Pablo da Silveira, diz respeito à solução pensada por Rawls para dirimir os "conflitos que resultarem da concorrência dos direitos básicos entre si". Vimos que Rawls não reconhece, para a regulamentação da Constituição doS Povos, direitos básicos individuais aos cidadãos, mas interesses fundamentais aos povos constituintes. Nesse caso Rawls critica o liberalismo econômico por não equilibrar, no âmbito doméstico, certos direitos básicos dos cidadãos, tais como os relacionados aos princípios da liberdade e da igualdade. Essas duas exigências têm sido, de modo geral, no liberalismo econômico, desvinculadas, possibilitando a distribuição da primeira - da liberdade, sem levar em conta a segunda como alvo a atingir - a igualdade. O liberalismo econômico, escreve Rawls, "[...] permite desigualdades sociais e econômicas excessivas, pois the falta a exigência da reciprocidade. ${ }^{\text {"31 }}$

As conseqüências políticas, sociais e morais do liberalismo econômico aparecem claramente como desequilíbrio e conflito entre a posição econômica de um cidadão e a do seu vizinho. Rawls crê ter encontrado - na exigência da reciprocidade que ele considera elemento central da razoabilidade - a solução para resolver os conflitos resultantes da concorrência de direitos básicos, expressão de Pablo da

Ibid., p. 18 e p. 34

so "... What distinguishes peoples from states - and this is crucial - is that just peoples are fully prepared to grant the very same proper respect and recognition to other peoples as equals. Their equality doesn't mean, however, that inequalities of certain kinds are not agreed to in various cooperative institutions among peoples, such as the United Nations, ideally conceived. This recognition of inequalities, rather, parallels citizen's accepting functional social and economic inequalities in their liberal society." RAWLS, Ibid., p. 35

RAWLS, Tbid., p. 49 
Silveira na verdade não adotada por Rawls, que prefere falar, como já dito acima, de interesses básicos ou de interesses fundamentais dos povos, e não de direitos básicos dos cidadãos, quando se refere à Constituição dos Povos.

Com relação à terceira questão, a da igualdade de oportunidades, ainda uma vez Rawls concede não impor aos povos não liberais um modelo de seleção e atribuição de cargos e funções criado para atender aos cidadãos considerados livres, iguais, racionais e razoáveis, de acordo com um conceito de pessoa igualmente originado da concepção liberal da mesma como indivíduo dotado de poderes morais que não podem ser violados pela constituição. Em The Law of Peoples Rawls nos faz lembrar que mesmo as sociedades que se autoproclamam liberais não têm conseguido realizar esse ideal de igualdade. Não há, entre os regimes liberais, nenhuma padronização do ideal da igualdade de oportunidades, razão pela qual, para o âmbito doméstico, ele propõe o princípio da igualdade eqüitativa de oportunidades. ${ }^{32}$

Desse modo, dado que não fazem o que elas mesmas proclamam - razão pela qual Rawls escreve Uma teoria da justiça, para aperfeiçoar sociedades bemordenadas do ponto de vista jurídico, mas imperfeitas do ponto de vista da justa distribuição de oportunidades - não têm moral para punir as sociedades hierárquicas decentes por não oferecerem igualdade de oportunidades aos seus membros. Não é demais lembrar que as sociedades não liberais reconhecem e assumem publicamente que não fazem a distribuição de cargos, funções e salários de acordo com o princípio da igualdade de oportunidades. As sociedades que se autoproclamam liberais escamoteiam, na verdade, o fato de que também distribuem tais bens por outras vias que não a daquele princípio. A diferença, por outro lado, pode ser notada no esforço que fazem para corrigir os desvios do princípio da igualdade de oportunidades, através da política de ação afirmativa. ${ }^{33}$ Qualquer intervenção em sociedades não liberais, em nome do não respeito ao princípio da igualdade de oportunidades, näo teria legitimidade, pois esse princípio não faz parte da Constituição dos Povos. Ele é um princípio oriundo de uma concepção particular de bem, portanto, de uma teoria ampla, não da razão política pública. ${ }^{34}$

A quarta questão que Pablo afirma não ter sido considerada por Rawls em sua primeira versão de The Law of Peoples, recebe alguma atenção do Autor na versão de 1999. De que modo são assegurados recursos para que os cidadãos tenham acesso aos bens básicos? Encontramos no texto de Rawls a distinção entre dois casos diferentes: o de sociedades hierárquicas e decentes, em relação às quais as liberais não devem sugerir nem impor nenhum modelo de fora para assegurar a

32 Cf. RAWLS, Uma teoria da justiça. Lisboa: Presença, 1993, cap. II, § 14.

${ }^{33}$ Para aqueles que se interessam mais de perto, sugiro a leitura dos livros Ética Prática, de Peter Singer, em especial o capítulo 2 no qual trata do problema da igualdade e de suas implicações, e o livro de Cornel West, Questão de Raça, cujo capitulo 5 é dedicado à crítica dos programas de cotas, ou ação afirmativa experimentados nos EUA nas últimas três décadas.

${ }^{34}$ RAWLS, LOP, p. 84 
distribuição de bens básicos aos cidadãos, e o das burdened societies ${ }^{35}$ condenadas pela natureza, pela história, ou pela cultura a enfrentar dificuldades para criar instituições justas de distribuição de bens. No primeiro caso, as sociedades devem recorrer, no seu entender, ao FMI e não à $\mathrm{ONU}{ }^{36}$ No segundo caso Rawls reconhece o dever de ajudar. ${ }^{37}$ Lembra, porém, com base em três questões já analisadas em Uma teoria da Justiça, ${ }^{38}$ que para tornar-se bem-ordenada nenhuma sociedade precisa, de fato, ser rica: a) a poupança justa deve ser feita com a finalidade de assegurar a todos uma vida digna, nada além disso; b) a poupança justa só deve ser obrigatória para assegurar o fornecimento de bens no futuro; c) não é preciso grande riqueza para que uma sociedade construa instituições justas ou decentes. Esses três pontos indicam como poupar, no âmbito doméstico, e como orientar a ajuda no plano internacional, a fim de "destinar recursos para assegurar aos indivíduos os bens básicos". ${ }^{39}$

De qualquer modo, tanto a poupança - no âmbito doméstico, quanto a ajuda - âmbito internacional, devem ser para fomentar, preservar ou criar instituições justas, não para aumentar a riqueza de grupos particulares. Rawls sugere três organizações para cuidar dos interesses básicos dos povos constituintes: uma para assegurar o comércio entre os povos, outra para permitir aos povos financiamentos de um sistema bancário cooperativo, e uma outra com funções hoje exercidas pela ONU. ${ }^{40}$ Não estranha que seu esquema ecoe três siglas bem conhecidas: OMC, FMI e ONU, confirmando nesse ponto, a hipótese de que sua teoria assenta sobre a escola liberal e suas instituições. Não há, no texto de Rawls, qualquer suspeita de que sejam essas mesmas instituições responsáveis pelo desastre econômico que levou nas duas últimas décadas à concentração de riquezas mundiais nas mãos de menos de um quarto da população do planeta, concentrada, diga-se de passagem, nos países que fundaram tais mecanismos de comércio, de proteção ao capital e de defesa da soberania desses interesses no plano internacional. Se, porém, a Constituição dos Povos levar a uma injusta distribuição, ela deve ser corrigida com base no dever de ajuda mútua, que significa, para Rawls, “... o dever que povos liberais e decentes têm de dar assistência às sociedades oprimidas (burdened societies), (...) que não são nem liberais nem decentes. ${ }^{41}$

\footnotetext{
${ }^{35}$ Tenho traduzido burdened societies por 'sociedades oprimidas', ou 'sociedades em condiçöes hostis à institucionalização da justiça'. Tomo tal liberdade, dado que ainda não foi traduzido para o português The Law of Peoples. A mesma audácia experimento ao traduzir de modo não convencional o projeto que dá o título à obra, isto é, não como Direito dos Povos, mas Constituição dos Povos. Respeito a idéia de Rawls, o qual, por sua vez, a herdou de Kant, de evitar propor algo que pareça com a apologia da construção de um Estado Mundial, de um Governo Mundial sobre o qual todo direito assentar-se-ia. Trabalhando com a expressão Constituição dos Povos enfatiza-se o processo constituinte, a necessidade do debate, da reflexão, da fundamentação do modelo que visa garantir a liberdade, a igualdade e a paz no âmbito internacional.

36 RAWLS, LOP, p. 84

37 RAWLS, Ibid., p. 106

RAWLS, Uma teoria da justiça, § 44

3 RAWLS, LOP, p. 107

40 Cf. RAWLS, Ibid., p. 42

${ }^{41}$ Cf. RAWLS, Ibid., p. 43 nota 53
} 
Mas, Rawls não ilude aqueles que gostariam de ver em sua obra uma defesa da justa distribuição da riqueza no plano internacional. Quando parece que vai tomar posição favorável a essa distribuição, ele escorrega para teses conservadoras e afirma que a riqueza de um povo assenta: 1) na tradição de sua cultura religião, filosofia e moral; e 2) nos dons empreendedores e cooperativos, fundados na virtude política de seus membros. ${ }^{42}$ Deve-se ajudar para combater a fome, mas, principalmente, para que os direitos humanos sejam cumpridos. Rawls admite, nesse ponto, a tese irreprochável de Amartya Sen, de que o problema da fome não se deve à falta de alimentos, e sim à falta de distribuição dos mesmos de acordo com um princípio justo. Comida e riqueza concentradas, e não escassez de alimentos ou de riquezas, são, de modo geral, a causa da fome e da miséria. Tratase, pois, de um problema moral, não de um problema econômico. Por essa razão, toda ajuda deve ser moral. A finalidade de toda ajuda é levar a sociedade em questão a administrar a solução de seus problemas, de tal modo que possa fazer parte, com a mesma autonomia e dignidade, isto é, em condições de igualdade em relação às demais, da constituição dos povos. ${ }^{43}$

Rawls admite um princípio de ajuda emergencial para fazer chegar os recursos destinados a assegurar os bens básicos aos cidadãos que constituem os povos associados, mas, do mesmo modo como Robert Nozick o faz em Anarquia, Estado e Utopia, ${ }^{44}$ teme um esquema permanente de ajuda ao mesmo povo, pois, em vez de torná-lo igual, o colocaria na condição de dependente, quem sabe mesmo, de mal-acostumado. ${ }^{45}$

Pablo afirma de modo procedente, que Rawls, na verdade, já no âmbito doméstico, no primeiro âmbito de sua teoria da justiça, não trata dos problemas decorrentes do fato de que as condições objetivas e subjetivas da justiça democrática ${ }^{46}$ podem estar presentes apenas de modo parcial ou até mesmo incipiente, tanto nas sociedades liberais quanto nas demais. Aqui é bom lembrar que em nenhum momento Rawls sugere que seu modelo sirva para distribuir a riqueza em sociedades altamente desiguais. Para isso os cidadãos devem recorrer a outros modelos, quem sabe até à revolução armada. O modelo de Rawls pressupõe, desse modo, o amadurecimento dos cidadãos dentro dos princípios que o próprio modelo de justiça afirma querer construir: desejo de exercer poderes morais, racionalidade, razoabilidade, sentido de justiça. ${ }^{47} \mathrm{O}$ fundamento ou a cultura de fundo que o modelo pressupõe não existe ainda.

Assim, no entender de Pablo da Silveira, não teríamos na verdade um problema de circularidade, mas de sustentabilidade da proposta (estabilidade), pois, para

\footnotetext{
RAWLS, Ibid., p. 108

43. RAWLS, Ibid., p. 110-111

44 Robert NOZICK, Anarchy, State, and Utopia. USA, Library of Congress Catalog, Basic Books, 1974. Part II, Chapter 7: Distributive Justice, Section II, p. 183-231

45 RAWLS, LOP, p. 117

45 Cf. FELIPE, Sônia T. "Justiça: igualdade eqüitativa na distribuição das liberdades". In: FELIPE, Sônia T. Justiça como Eqüidade, p. 43

4) SLVEIRA, Pablo da. Op. cit., p. 352-3
} 
que possa ser implementada, ela requer que as pessoas tenham atingido o padrão moral que o projeto ainda precisa fomentar. Lendo a nota 15 de The Idea of Public Reason vê-se que Hollenbach tenta dizer quais são os setores que constituem a cultura de fundo, concluo que o problema não se resume ao fato de que não temos uma cultura de fundo sobre a qual se assenta a concepção de justiça que privilegia um conceito de pessoa moral dotada do desejo de exercer tal poder, mas no fato de que, em todos os espaços nos quais exercemos nossos poderes morais, dentre eles, muito especialmente o poder da expressão das idéias, não há lugar para o debate sobre o bem comum, ou sobre a justa forma de distribuir tal bem. Em se tratando disso, tanto nas universidades quanto nos centros de arte ou mesmo na imprensa, sem exceção, todos os formadores de opinião, como se gosta de dizer em nossa língua, não pronunciam, no espaço público, uma concepção verdadeiramente política de justiça. Quando falam do assunto o fazem influenciados sempre ainda por suas intuições, ou seja, pelas idéias cultivadas em seus grupos privados. Embora tenhamos em nossa Constituição os princípios que Rawls adota para formular seu modelo de justiça, falta-nos, de verdade, o sentido dessa justiça, que se faz acompanhar da vontade de ver todas as instituições públicas responsáveis pela distribuição de bens, orientarem essa distribuição com vistas a possibilitar realmente a todos os cidadãos o acesso aos mesmos.

Assim, o problema da democracia e não apenas dos fundamentalismos, reside no vazio que se estabelece no espaço público, entre a razão pública - os discursos pronunciados pelos mandatários juízes, governantes e parlamentares, que devem, conforme vimos acima, justificar suas decisões com base em uma teoria da justiça - e a razão política - o discurso dos cidadãos inconformados com o que ouvem, pelo fato de que o que ouvem não parece bater bem com o que supõem devesse ser a concepção de justiça defendida pelas decisões políticas. Desgostosa da política e, conseqüentemente, da justiça, a cultura de fundo deixa de ser a cultura política dos cidadãos. O que se produz de reflexão nesses espaços não chega a se constituir substancialmente em conteúdo teórico seguido pelos poderosos para justificar suas ações. Não há, pois, uma teoria do bem comum, embora, em nosso país, todos se justifiquem alegando querer protegê-lo.

Penso ter contribuído acima para continuar a reflexão sobre os problemas do consenso justaposto e da apatia política levantados por Pablo na análise do texto de Rawls. Concordo com Pablo da Silveira, que Rawls deixa sem resposta algumas questões, tais como: $1^{\text {a) }}$ Se é a cultura de fundo que possibilita o consenso justaposto, base da estabilidade, como é que se garante essa mesma cultura, sem a qual tudo o mais não pode ser garantido? Rawls não teria atendido a essa questão, entende Pablo, porque o consenso justaposto só é possível, de fato, entre aqueles que já compartilham da concepção das instituições democráticas. 2â) Como enfrenta Rawls o maior problema político, qual seja, não o da intolerância, mas o da apatia, ou o desinteresse dos cidadãos por qualquer teoria política da justiça? 3) Como compatibilizar Direitos Humanos com intervenção armada e sanções econômicas, dado que não se pode pretender garantir a paz no âmbito 
internacional, sem levar em conta o peso que representam nesse plano, as sociedades não liberais? ? $^{48}$

Em seu trabalho de 1997 Pablo da Silveira faz a Rawls duas exigências: $1^{1 \mathfrak{a}}$ a de uma redefinição de razão pública, como condição e recurso para que se possa efetivamente alcançar o consenso justaposto; algo que Rawls faz, mas, a meu ver, piorando o estado do modelo, ao separar a cultura de fundo da atividade de justificação pública dos governantes, e $2^{\underline{a}}$ a não separação entre moral pessoal e razão política ou razão pública na discussão da teoria da justiça. Pablo sugere, por fim, e estou de acordo com sua posição, que se constitua, definitivamente, um espaço público como lugar onde sejam construídas as pontes entre as concepções privadas de bem e a concepção política da justiça, exigência essa feita pelo próprio Rawls desde seu primeiro livro.

Algo nessa direção aparece, embora muito timidamente, na sugestão de Rawls, de que seja constituído um fórum internacional permanente de denúncias contra violações dos direitos humanos e da constituição dos povos. Nesse organismo poder-se-ia manter aceso o debate entre sujeitos representativos das concepções amplas e aparentemente irreconciliáveis de bem, testando-se, desse modo, o consenso justaposto, a estabilidade, e o ideal da reciprocidade como meta de transformação da racionalidade em razoabilidade, superando-se, o desejo de buscar apenas fins particulares, até alcançar o ideal de moralidade que estabelece todos os povos do mundo como o fim comum a ser preservado.

\section{Referências bibliográficas}

FELIPE, Sônia T. “A concepção pública de justiça em John Rawls". In: Seqüência. Florianópolis, 17(33): 129-136, dez. 96

— . "A relação crítica de Rawls com a filosofia política". In: Filósofos. Goiânia, 4(1): 105-123, jan.jun. 99

_ . "John Rawls: uma teoria ético-política da justiça". In: OLIVEIRA, Manfredo A. \& DE SOUSA, José Maria Arruda (Orgs.) Correntes Fundamentais da Ética Contemporânea. Petrópolis: Vozes, 2000.

- "Justiça integra. A teoria da justiça como 'fairness' em John Rawls". In: Filósofos. Goiânia, 2(1):101-107, jan.-jun. 97

- "Justiça: igualdade eqüitativa na distribuição das liberdades". In: FELIPE, Sônia T. Justiça como Eqüidade. Anais do I Simpósio Internacional sobre a Justiça. Florianópolis: Insular, 1998. 4357

- "Liberais e fundamentalistas: ideais e limites da utopia rawlsiana de uma Constituição dos povos." In: LIMA, Cime (Org.) Festchrift em Homenagem a Manfredo de Oliveira. (No prelo)

- "Rawls: entre o socialismo real e o capitalismo liberal. Uma teoria da justiça dá ênfase à eqüidade." In: Filósofos. Goiânia, 1(2): 89-96, jul.-dez. 96

. "Direitos Humanos: vias e vieses da Politica Internacional em The Law of Peoples." Palestra proferida no II Simpósio Internacional sobre a Justiça. Porto Alegre RS, 21 de agosto de 2000

\footnotetext{
${ }^{48}$ Não trato aqui dessas questōes levantadas pela obra. O problema dos direitos humanos em The Law' of Peoples que Pablo da Silveira considera o terceiro problema, abordo em outro texto, publicado como Anais do II Simpósio Internacional sobre a Justiça, ao tratar das críticas feitas no I Simpósio Internacional sobre a Justiça por Klaus-Gerd Giesẹn a Rawls, em artigo intitulado: O charme perdido do liberalismo político.
} 
GIESEN, Klaus-Gerd. "O charme perdido do liberalismo politico." In: FELIPE, Sônia T. (Org.) Justiça como Eqüidade. Anais do I Simpósio Internacional sobre a Justiça. Florianópolis: Insular, 1998. p. 365-381

NOZICK, Robert. Anarchy, State, and Utopia. USA, Library of Congress Catalog, Basic Books, 1974

RAWLS, John. "The Idea of Public Reason Revisited". In: The Law of Peoples. Cambridge MA/London UK: Harvard University Press, 1999

- "The Law of Peoples". In: SHUTE, Stephen and HURLEY, Susan (Eds). On Human Rights. The Oxford Amnesty Lectures 1993. New York: Basic Books, 1993

ـ Political Liberalism. New York: Columbia University Press, 1993

. The Law of Peoples. Cambridge MA/London UK: Harvard University Press, 1999

- Uma teoria da justiça. Lisboa: Presença, 1993

SARTOR, Vicente Volnei de Bona \& FELIPE, Sônia T. "Bens primários em John Rawls." In: Phrónesis. Campinas, I (3): 11-32, set./dez. 1998

SLVEIRA, Pablo da. "La teoria rawlsiana de la estabilidad: overlapping consensus, razón pública y discontinuidad." In: FELIPE, Sônia T. (Org.) Justiça como Eqüidade. Anais do I Simpósio Internacional sobre a Justiça. Florianópolis: Insular, 1998. p. 345-363

SINGER, Peter. Ética Prática. São Paulo: Martins Fontes, 1993

WEST, Comel. Questão de Raça. São Paulo: Cia. das Letras, 1994. 